$\xi=1$ 国

\title{
Performance Evaluation of Thermal Enhanced Oil Recovery by In-situ Combustion
}

\author{
D.Sairam ${ }^{1}$, G. Reshma ${ }^{2}$, Arjun. P ${ }^{3}$, Y. Deepu ${ }^{4 *}$ \\ ${ }^{4}$ Assistant Professor, Department of petroleum engineering, Koneru Lakshmaiah Education Foundation, \\ Vaddeswaram, Guntur, AP, India - 522502 \\ ${ }^{1,2,3}$ Department of petroleum engineering, Koneru Lakshmaiah Education Foundation, Vaddeswaram, Guntur, AP, India - 522502 \\ *Corresponding author E-mail: deepu.y2@gmail.com
}

\begin{abstract}
Thermal methods of enhanced oil recovery and especially the in-situ combustion known to the efficient methods among the known enhanced oil recovery methods. In this method heat is added to the reservoir to reduce the oil viscosity. So, that it can be more efficiently driven to the producing well. However the experimental analysis of ISC to understand its operation is known to be expensive. Therefore we have developed a 1D model using STARS module of CMG where in we have Cartesian grid. To this we have given and given $\mathrm{i}, \mathrm{j}, \mathrm{k}$ values. Later porosity, Temperature and initial pressures are given. For setting the well we have used injector and producer. After checking errors we have validated the model. It is evident from the performance plots that the temperature along the core is a function of the gas injected and the oil saturation. However the as the temperature moves along the reservoir from injection well the oil saturation is observed to decrease in the vicinity of the well and start to build away from the injection well towards the production well. This is work provides a platform to understands the combustion propagation and its role in improving the oil recoveries
\end{abstract}

Keywords: In-situ combustion, CMG STARS, Temperature, Oil Saturation, modelling.

\section{Introduction:}

In-situ combustion (ISC) is an enhanced oil recovery (EOR) technique to produce (medium) heavy oil where energy is generated by a combustion front that is produced along the reservoir by injecting air. The process can be classified as a combination of a thermal method and a gas injection recovery method. The moving combustion front is produced by a continuous flow of air/oxygen. From the injection well, the burned zone a part of reservoir is swept by the combustion front. In the combustion area injected oxygen reacts with the residual hydrocarbons and generates $\mathrm{CO}_{2}$, $\mathrm{H}_{2} \mathrm{O}$, and heat. ISC is the burning of fuel which exists in rocks of the reservoir. The interpretation of ISC is "the production of a high temperature front for which the fuel is a coke-like substance laid down by thermal cracking reactions" (Moore et al., 1999). It is a displacement process in which air containing gas is injected from the reservoir where it reacts with the crude to generate a high temperature(HT) combustion front which is produced from the reservoir. The heat generated is used to recover the oil in place. Combustion is started in the formation by injecting air that is heated.

Depending upon the initial temperature of the reservoir, the oxidation temperature tendency of the crude oil is being provoked. Usually the air is initially preheated at the sand face of the injection well by using an electrical heater or by some other convenient techniques. However, in some other reservoirs, the oil provokes after the air has been injected over some period. Since the combustion reactions are heat sensitive and the deep formations having high initial temperatures which results in the occurrence of ignition.
Basically, enhanced oil recovery has a various type of categories such as (1) thermal, (2) carbon dioxide and (3) chemical flooding

Thermal recovery is the most and best advanced technique more over it is the best technique to recover oil in place. It adds heat to the reservoir and reduces the oil viscosity. So, that it can be more efficiently driven to the producing well. Here, driving force is pressure that pushes the oil. There are two processes under thermal recovery (1) in-situ combustion and (2) steam injection. Here, we mostly concentrate on in-situ combustion only.

Carbon dioxide flooding is a tertiary method. This method is chosen when the reservoir pressure is depleted through primary and secondary production but thermal recovery is more effective when compared to carbon dioxide flooding.

Based on these flooding process thermal EOR is best method to simulate the reservoir data. Here we moving on to the thermal recovery. In the thermal process we concentrated on in-situ combustion.

In this process heat is initiated by pumping air into the burning part of oil to reduce the consistency of the crude. That drives it forward by combustion of steam, hot water, and gas drive. Finally, production is attained at production wells. In some cases, the capability of total ISC process can be revised by altering water and air injection. The injected water is transferred through the hot rock. Due to density, injected air overdrives the oil in place. Gravity causes extensive overriding problems. Steam flooding may play 
more efficient process. In-situ combustion will apply for both low gravity oil as well as high gravity oil reservoirs.

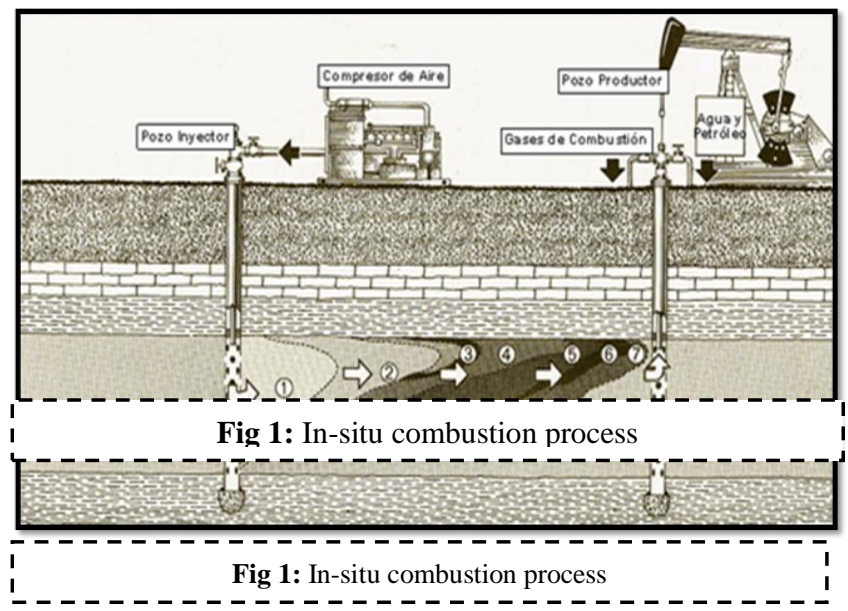

\section{Conditions Required for ISC Process}

Author (Sarathi 1999) explained that in some cases, steam injection, the process of ISC is the most applicable enhance heavy oil recovery method. The main requirements of ISC are as follows:

1. Thermal technique is one of the highly adequate method of oil recovery, in this process heat is reducing the consistency of oil. Even though no combustion will take place without heat.

2. Air is essentially required to hold the combustion front efficiently. It is the most accessible injecting fluid and it is economical.

In addition to the above conditions, ISC is accepted that the process is economically inexpensive method in the following reservoir conditions (Burger, 1972a, 1972b; Brigham, 2006; Turta, 1994):

- In shallow reservoirs ISC is a very effective method but it is complicate, and it can be used for a shallow reservoir for recovering the $10-20^{\circ}$ API heavy oil in which conventional techniques cannot be succeeded due to the oil density.

> In deep reservoirs improving the recovery of light oil about $>30^{\circ} \mathrm{API}$. Therefore, the technique can be applied as an additive to the water and steam flooding processes. Steam injection is not suitable when it is treated with in a deeper reservoir, for the heat loss and water flood due to the commercial implication involved while lifting which made the process repulsive. In such conditions combustion and gas are the only processes which are applicable.

It is an ideal process for which a thin formation of oil sand bodies diameter varies from 121.92 to $4572 \mathrm{~cm}(4-150 \mathrm{ft})$ and it was successful and effective in 304.8 to $1524 \mathrm{~cm}(10-50 \mathrm{ft})$. It is already considered that ISC can be applied in the thin oil zone when it is correlated to other techniques.

$>$ The indication of change in reservoir temperature is less adverse fallout on the combustion process when compared to various techniques such as steam injection and water flooding processes which is generally affected by the change in temperature.

$>$ The formations with permeability ranges between 5 to $10,000 \mathrm{mD}$ can be used in ISC processes. (Sarathi 1999)

\section{Methodology:}

Model Description: Here we have developed a 1D model using the data given below. After collecting the data by selecting STARS we have given input values and selected Cartesian grid and given $\mathrm{i}, \mathrm{j}, \mathrm{k}$ values. Later porosity, Temperature and initial pressures are given. For setting the well we have used injector and producer. After checking errors we have validated the model. After the results are obtained we have taken the images of results and shown below.

\section{Modelling Data:}

System dimensions:

In this simulator file we have created cartesian grid system with 19 blocks and I, J, K values are (19 1 1). By using the below data, we have executed the below tables in CMG software by using STARS.

We have taken the results of (N. Makwashi 2017) and executed the data in the CMG software and the results were shown in different intervals. Here, we have taken temperature and oil saturation profiles to understand and analyses the flow in the reservoir.

Table 1: System Properties

\begin{tabular}{|l|l|l|}
\hline Properties & Value & Units \\
\hline Block Length & 1.85 & $\mathrm{~m}$ \\
\hline Block Width & 0.0882 & $\mathrm{~m}$ \\
\hline Porosity & 0.415 & -- \\
\hline Permeability(i,j,k) & 14.0 & $\mathrm{D}$ \\
\hline Temperature & 72 & ${ }^{\circ} \mathrm{C}$ \\
\hline Saturation & 0.3 & -- \\
\hline Pressure & 1952 & $\mathrm{psi}$ \\
\hline
\end{tabular}

Table 2: Heat transfer and Saturation Properties

\begin{tabular}{|l|l|l|}
\hline Properties & Value & Units \\
\hline Axial grid blocks & 19 & -- \\
\hline Initial water saturation $\left(\mathbf{S w}_{\mathbf{i}}\right)$ & 0.118 & -- \\
\hline Initial gas saturation $\left(\mathbf{S g}_{\mathbf{i}}\right)$ & 0.0 & -- \\
\hline Initial oil saturation $\left(\mathbf{S o}_{\mathbf{i}}\right)$ & 0.882 & -- \\
\hline Bottom hole pressure $(\mathbf{B H P})$ & 2014.7 & $\mathrm{psi}$ \\
\hline Thermal conductivity $(\mathbf{K})$ & 100 & $\mathrm{~J} / \mathrm{m}-\mathrm{min}-\mathrm{K}$ \\
\hline Heat transfer rate & 200 & $\mathrm{Btu} / \mathrm{hr}$ \\
\hline
\end{tabular}

\section{Results and Discussions:}

\section{Temperature property:}

Case 1: 0.00 day

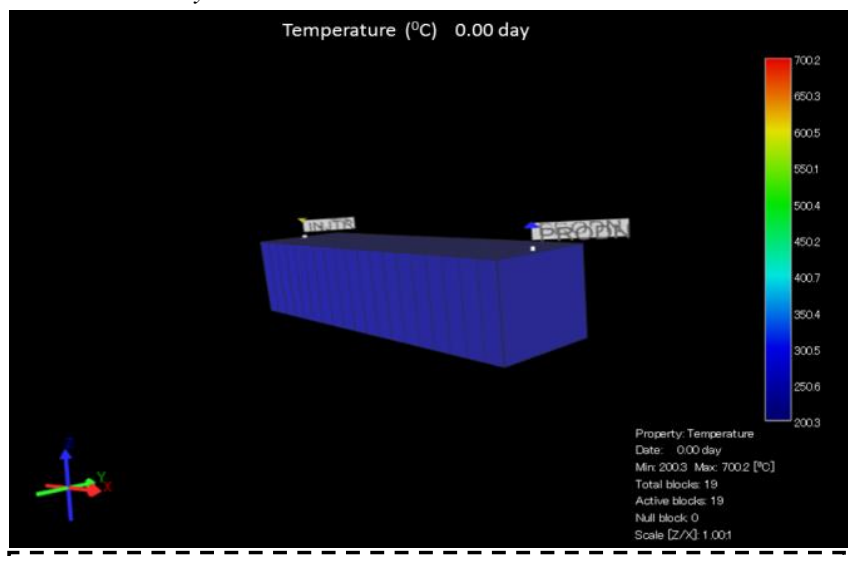

Fig 2: Temperature Profile at 0.00 day

The above Fig 2 represents the temperature result which is taken at 0.00 day. At first grid combustion takes place and the temperature is $200.3^{\circ} \mathrm{C}$ which is an initial temperature and no water or oil is injected and there is no heat loss in the reservoir. 


\section{Case 2: 0.0625000 day}

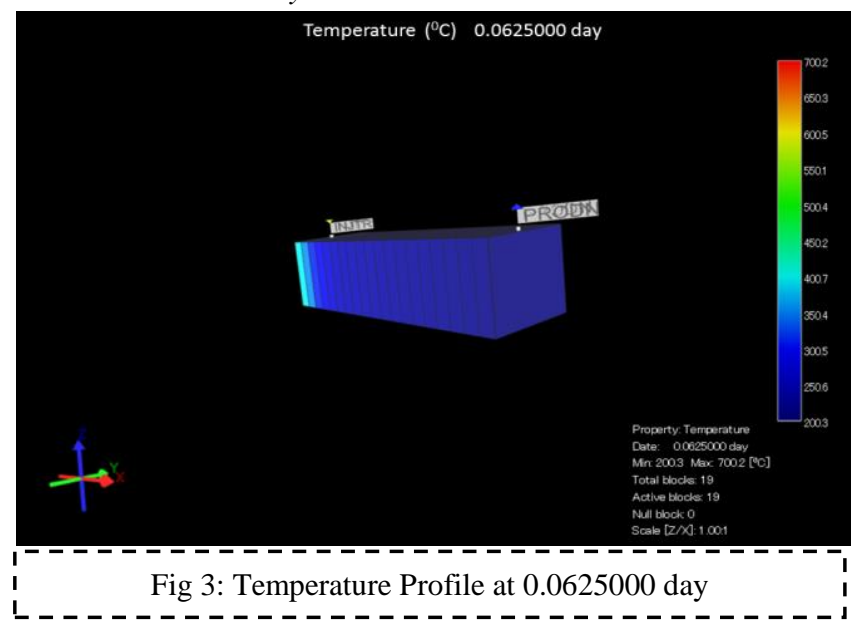

The above Fig 3 represents the temperature result which is taken at 0.0625000 day. Usually we injected hot air into the injection well at $0.0625000^{\text {th }}$ day and the temperature reaches to $400.2^{\circ} \mathrm{C}$ due to decrease in oil consistency and it tends to increase the temperature compared to previous day.

\section{Case 3: 0.13 day}

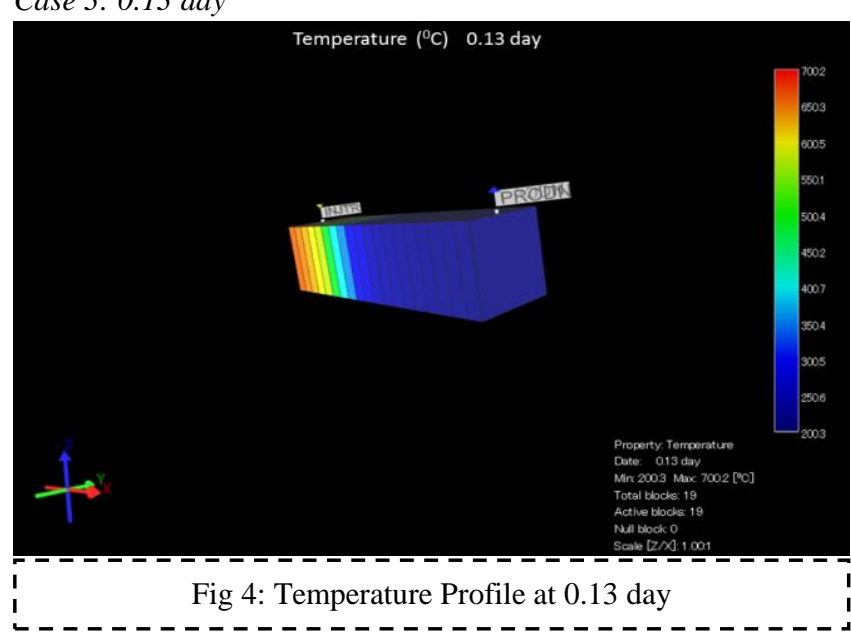

The above Fig 4 represents the temperature result which is taken at 0.13 day. Here grid 1 having approximately $648.3^{\circ} \mathrm{C}$ i.e., more heat capacity when compared to grid $6 \& 7$ having $400.7^{\circ} \mathrm{C}$. This temperature range indicates that change in temperature profiles to indicate the flowing of reduced viscous oil from one grid to another. Finally, at this day grid 1 is having more temperature when compared to 0.0625000 day.

Case 4: 0.19 day

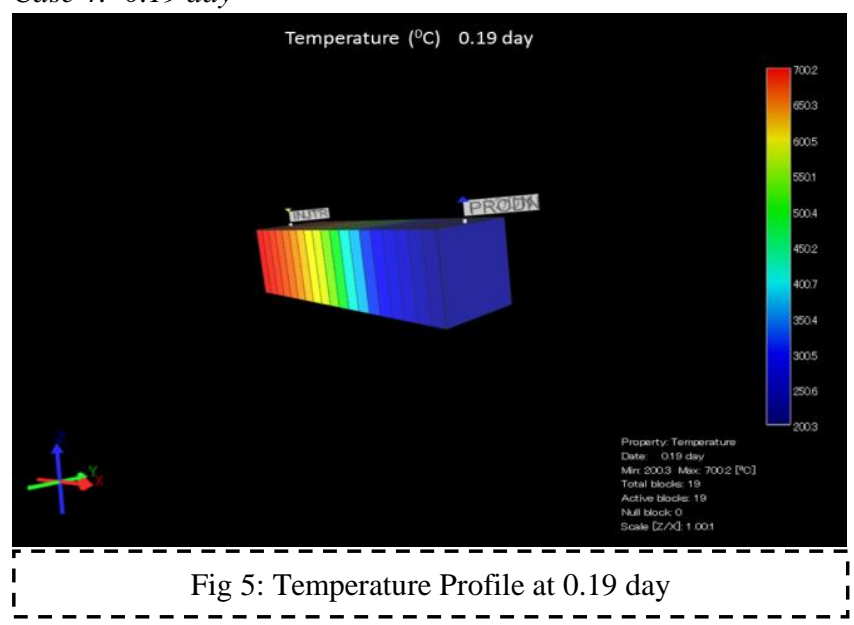

The above Fig 5 represents the temperature result which is taken at 0.19 day. For day to day the temperature is changing from grid to grid. In previous day grid 10 is having approximately $400.5^{\circ} \mathrm{C}$, now the same grid is having approximately $525.3^{\circ} \mathrm{C}$ which indicates the change in grid temperature. Previously grid 1 is having aproximately $648.3^{\circ} \mathrm{C}$, now it changes to $670.2^{\circ} \mathrm{C}$ which attains approximately high temperature than previous day grid.

Case $5: 0.50$ day

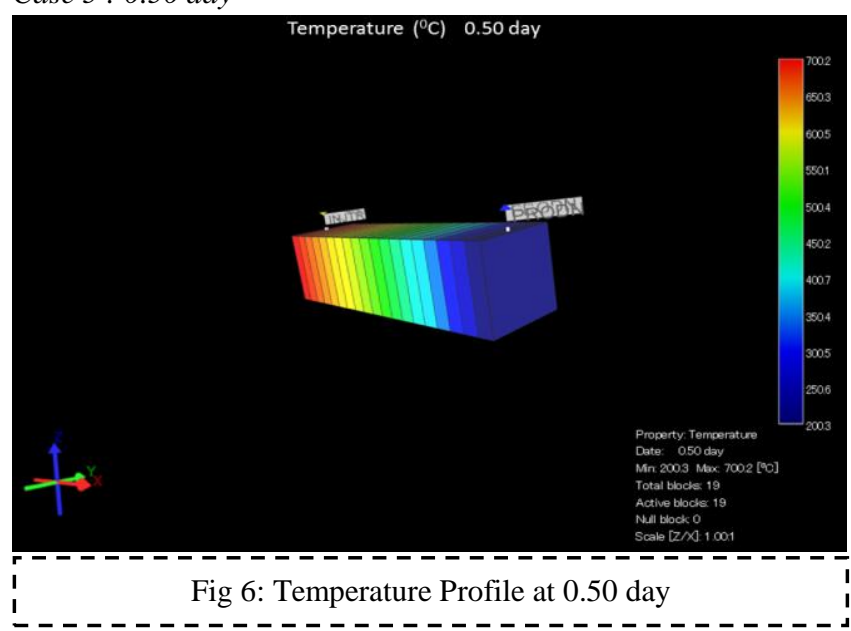

The above Fig 6 represents the temperature result which is taken at 0.50 day. Here the grid 1 attains maximum temperature of $700.2^{\circ} \mathrm{C}$, and $6 \& 7$ grids are having temperature of $600.3^{\circ} \mathrm{C}$ and $10 \& 11$ grids are having $530.2^{\circ} \mathrm{C}$, and $15 \& 16$ grids are having the temperature of $400.3^{\circ} \mathrm{C}$ and remaining grids are aproximately $200.3^{\circ} \mathrm{C}$ to $230.5^{\circ} \mathrm{C}$ yet to be viscous.

Similarly, we have given the temperature input data and collected the temperature profiles with the same data we correlated with the temperature profiles to oil saturation profiles.

In oil saturation profiles we can identified the movement of viscous oil from pore spaces. And shown for different intervals of time/day.

\section{Oil Saturation property:}

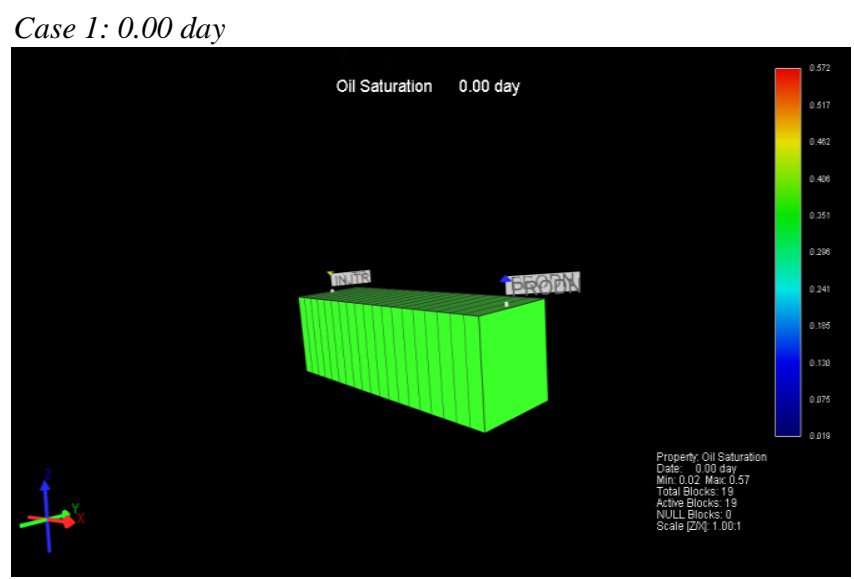

Fig 7: Oil Saturation Profile at 0.00 day the air or oxygen into injection well then the temperature of a reservoir tends to rise. The maximum and minimum values of oil saturation is 0.02 to 0.57 . At grid 1 the oil saturation at 0.00 day is having high saturation of 0.351 which indicates reservoir bed is high viscous in nature. 


\section{Case 2: 0.0625000 day}

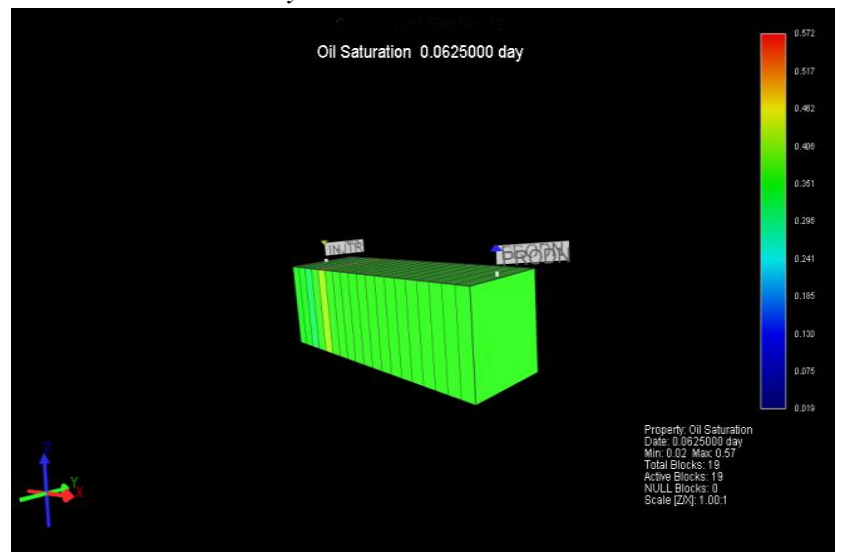

1
1

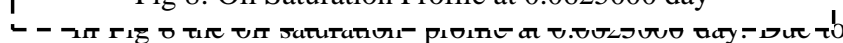
temperature effect the oil moment was observed in oil saturation profile ranges from 0.02 to 0.57 . At grid 1 the saturation value 0.351 , at grid 3 the value is 0.265 and at grid 5 the value 0.450 . That indicates the fluid in the porespaces tries to move towards another grid.

\section{Case 3: 0.13 day}

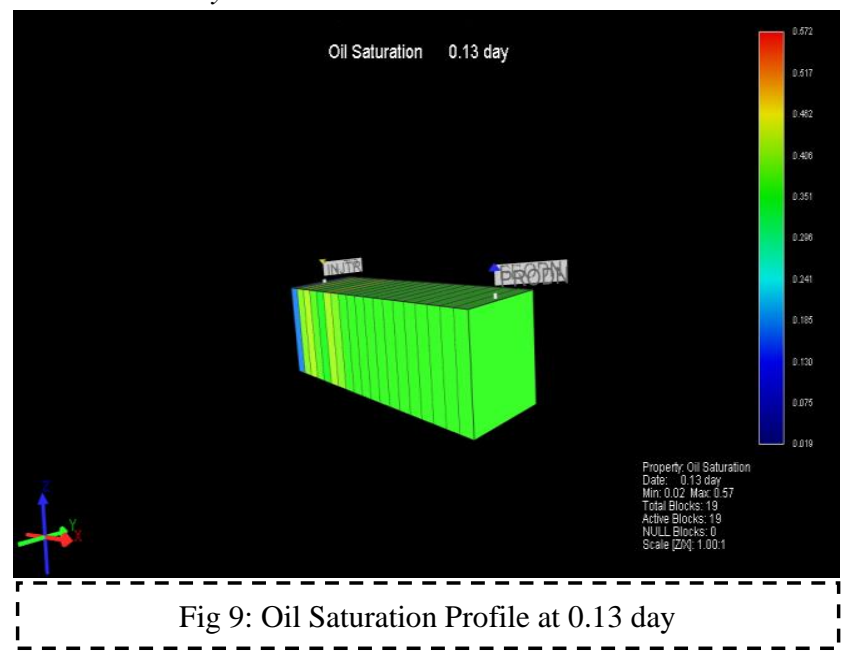

In Fig 9 the oil saturation profile at 0.13 day. The grid 1 having low oil saturation because the temperature initialised at the grid 1 and front is slightly moving towards the another grid due to temperature effect. Presently grid 1 having 0.185 saturation Similarly grid $2 \& 3$ also decrease saturation profile than the previous day. That shows decreasing the oil saturation with increasing the tempeature.

\section{Case 4: 0.19 day}

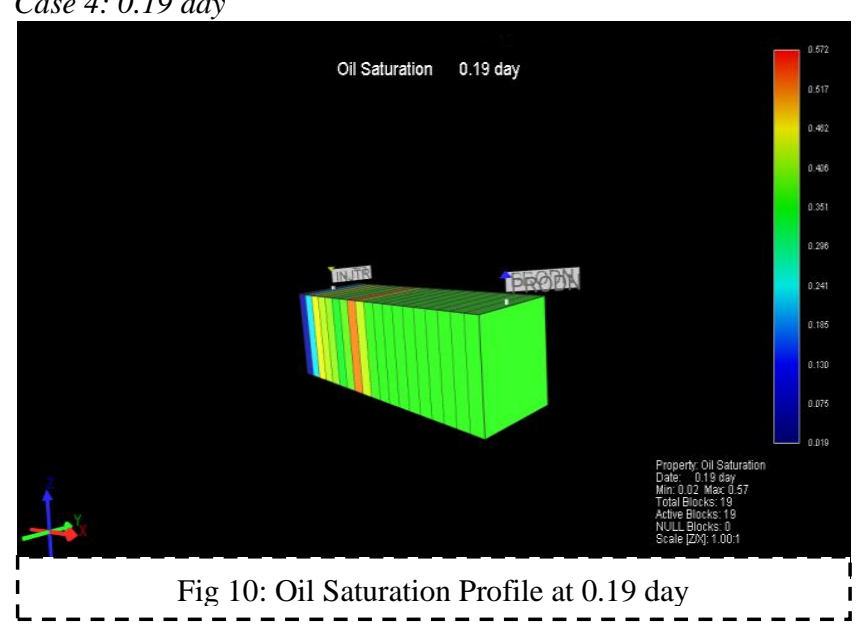

In fig 10 the saturation profile at 0.19 day. the grid 1 having the saturaion value 0.130 , at grid 2 value is 0.220 and at grid 8 value is 0.517 . the changing of the grid values shows the moment of the oil towdars another grid. that indicate chaning the temperature and decreasing the oil viscosity as well as oil saturation. which leads to produce moment of saturation profiles when compared to another day.

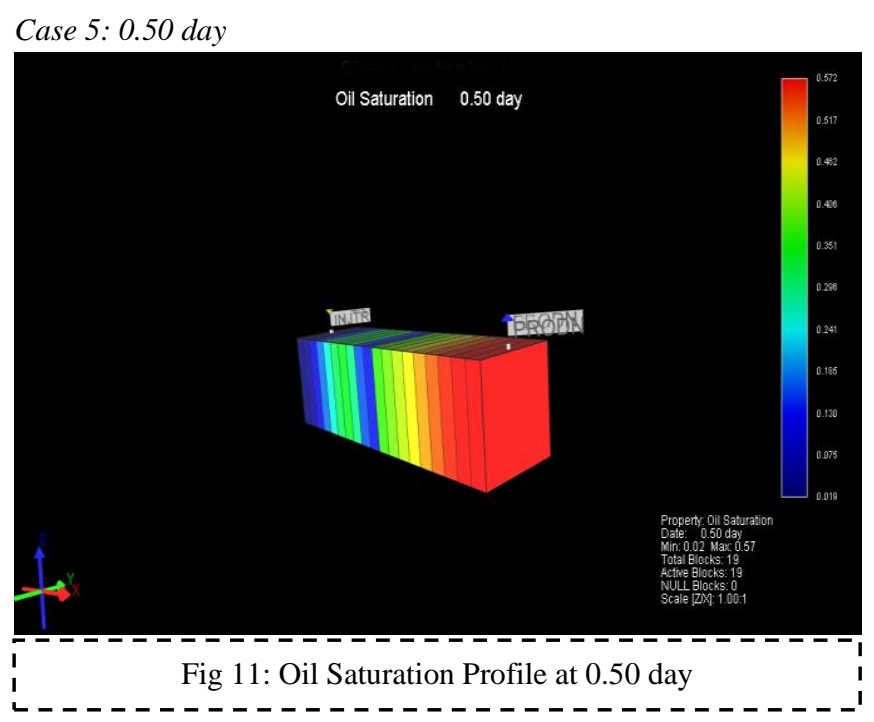

In fig 11 the saturation profile at 0.50 day. The maximum value attained at grid 1 due to temperature effect and the saturation value is 0.019; due to this effect the oil get less viscous. At grid 5 the saturation value 0.241 . And at grid 10 also having saturation of 0.019 and at $19^{\text {th }}$ grid the oil gets less viscous and get accumulated through porous media. And the oil saturation value at 19 grids is 0.572 .

\section{Conclusion:}

ISC challenges more physical and chemical processes compared to other methods. It is one of oldest thermal recovery method. This research work is committed to increase the oil production and to enhance the oil recovery. Here, the model is executed by using CMG STARS for various parameters. Certain parameters included here are Temperature and Oil Saturation. By sending the hot air into the well we observed that the changing the temperature from grid to grid. And change in saturation of oil in the porous media with respect to temperature. It is evident from the performance plots that the temperature along the core is a function of the gas injected and the oil saturation. However the as the temperature moves along the reservoir from injection well the oil saturation is observed to decrease in the vicinity of the well and start to build away from the injection well towards the production well. This is work provides a platform to understands the combustion propagation and its role in improving the oil recoveries

\section{References}

[1] Makwashi, N., Ahmed, T., Hameed, M.A., 2017. Influence of Injection Parameters Using CMG Stars. Journal of Emerging Trends in Engineering and Applied Sciences (JETEAS) 8(3):103-112.

[2] Burger, J, Sourieau, P., Combarnous, M., 1985. Thermal methods of oil recovery. Gulf Publishing Company, Book Division.

[3] Sarathi, P.S., 1998. In-situ combustion handbook-principles and practices.

[4] Turta, A., Chattopadhyay, S., Bhattacharya, R., Condrachi, A., Hanson, W., 2007. Current Status of Commercial in Situ Combustion Projects Worldwide. Journal of Canadian Petroleum Technology 46.

[5] Burger, J.G., 1972a. Chemical Aspects of In-Situ Combustion Heat of Combustion and Kinetics. Society of Petroleum Engineers Journal 12 
[6] Burger, J.G., 1972b. Chemical Aspects of In-Situ Combustion Heat of Combustion and Kinetics. Society of Petroleum Engineers Journal 12

[7] Brigham, W.E., Castanier, L.M., 2006. Chapter 16 Reservoir Engineering Section, in InSitu Combustion Handbook, Society of Petroleum Engineers,

[8] Burger, J., Sourieau, P., Combarnous, M., 1985. Thermal methods of oil recovery. Gulf Publishing Company, Book Division. 